Observational Report

\title{
Low Bone Mineral Density, But Not Epidural Steroid Injection, Is Associated with Fracture in Postmenopausal Women with Low Back Pain
}

Yuri Yi, MD, Byeongmun Hwang, MD, PhD, Heejeong Son, MD, PhD, and Ilyoung Cheong, MD, PhD

From: Kangwon National University Hospital, Chuncheon, South Korea

Dr. Yi is a Resident Physician with the Department of Anesthesiology and Pain Medicine, Kangwon National University, Chuncheon, South Korea.

Dr. B. Hwang and Dr. Son are Associate Professors with the Department of Anesthesiology and Pain Medicine, Kangwon National University, Chuncheon, South Korea.

Dr. Cheong is Professor with the Department of Anesthesiology and Pain Medicine, Kangwon National University, Chuncheon, South Korea.

Address Correspondence: Byeongmun Hwang, MD, PhD Department of Anesthesiology and Pain Medicine

Kangwon National University Hospital School of Medicine, Kangwon National University, Chuncheon,

Gangwon-do 200-701, South

Korea

E-mail:

arim14@kangwon.ac.kr

Disclaimer: There was no external funding in the preparation of this manuscript.

Conflict of interest: None.

Manuscript received: 05/29/2012 Accepted for publication: 07/26/2012

Free full manuscript: www.painphysicianjournal.com
Background: Therapy with glucocorticoids often results in bone loss and glucocorticoidinduced osteoporosis. However, the relationship between epidural steroid injection (ESI), bone mineral density (BMD), and vertebral fracture remains to be determined.

Objective: To establish a relationship between ESI, BMD, and vertebral fracture in postmenopausal women with low back pain.

Study Design: This study was a retrospective, nonblinded, cross-sectional clinical study. Setting: University-based pain management center.

Methods: We reviewed the medical records of postmenopausal women with low back pain who were treated with ESI. A total of 352 postmenopausal women were divided into 2 groups. Group 1 consisted of patients without fracture and Group 2 consisted of those with fractures. The results of BMD measurements, as well as any fragility fractures, the anatomical site involved, and the treatment administered, were also recorded. BMD was measured in the lumbar spine, femoral neck, and total femur after the treatment.

Results: Of the 352 patients, $218(62 \%)$ had no fractures while 134 (38\%) sustained a fracture. The age was significantly higher among patients who sustained fractures, and BMD at the lumbar spine, total femur, and femoral neck regions was significantly lower among patients who sustained fractures. In each region, the prevalence of osteoporosis was significantly higher in patients with fracture than in patients without fracture (all $P<$ 0.05). Age, height, and weight were associated with low BMD. However, our study showed no consistent correlation between BMD and the mean number of ESIs, mean total dose of glucocorticoids, or mean duration of ESIs.

Limitations: First, this study is limited by the fact that it was retrospective. Second, the number of cases receiving very frequent, high-dose glucocorticoid injections was very small.

Conclusions: Older age and lower BMD were associated with osteoporotic fracture in postmenopausal women treated for low back pain with ESI. The ESIs were not associated with low BMD or fracture.

Key words: Bone mineral density, epidural steroid injection, fracture, glucocorticoids, low back pain, postmenopause.

Pain Physician 2012; 15:441-449 


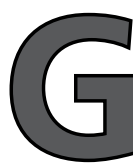

lucocorticoids are widely used in a variety of inflammatory, autoimmune, pulmonary, and musculoskeletal disorders. While glucocorticoids offer benefits, numerous adverse effects are described, which are directly related to both dose and duration of treatment, such as trunk obesity, moon face appearance, skin atrophy, disturbance in glucose and lipid metabolism, and osteoporosis (1-4). Indeed, glucocorticoids decrease bone mineral density (BMD) and increase bone fragility, resulting in a large increase in fracture risk (1-4). In the setting of epidural steroid injections (ESIs), a minimally invasive procedure used for the effective treatment of low back pain and sciatica (4-21), the development of osteoporosis and fractures is common $(2,6)$, especially in postmenopausal women $(1,22)$.

Osteoporosis is a skeletal disorder characterized by a decrease in BMD and the loss of structural and biomechanical properties of the skeleton, leading to increased risk of fractures as well as increased mortality and morbidity in the elderly $(1,23,24)$. Osteoporosis is classified as primary when occurring spontaneously, or as secondary when caused by another factor or disorder. Glucocorticoid-induced osteoporosis (GIOP) is the most common form of secondary osteoporosis $(23,24)$. GIOP started gaining the attention of physicians in the realization that, as compared to the normal population, patients with chronic low back pain undergoing ESIs have lower bone density at the lumbar spine and an increased incidence of osteopenia and osteoporosis (25). However, some studies have reported no significant change in bone density with epidural steroids $(26,27)$. Further, the relationship between ESI, BMD, and vertebral fracture has not been adequately studied.

To investigate whether the use of epidural glucocorticoids is correlated to vertebral fracture and BMD, we retrospectively analyzed the age; weight; height, BMD at the lumbar spine, femoral neck, and total femur; mean number of ESls; mean total dose of glucocorticoid administration; and mean duration of ESIs in postmenopausal women undergoing treatment for low back pain.

\section{Methods}

This study is a retrospective analysis of postmenopausal women with low back pain who were admitted to the pain management practice center of the Kangwon National University Hospital between January 2009 and December 2011. The study was designed according to STROBE (Strengthening the Reporting of Observa- tional Studies in Epidemiology) guidelines (28) and was approved by the local institutional review board. The study was registered with the Korea Clinical Trial Registry (Code K1202-012) and conducted in accordance with the Declaration of Helsinki. We carried out interviews based on reviews of the patients' medical records.

A total of 352 patients aged 50 years and older who satisfied the inclusion criteria were enrolled in the present study. The patients were divided into 2 groups. Group 1 consisted of patients without fracture and Group 2 consisted of those with fractures.

The inclusion criteria for the study were postmenopausal women with a medical history of ESI for low back pain, and women who had radiographs and BMD assessments performed after treatment for low back pain. The exclusion criteria were a history of comorbidities known to affect bone metabolism, such as cancer, pituitary diseases, thyroid disease, rheumatic disease, renal failure, or adrenal disease; a history of taking medication known to affect bone metabolism; vertebral fractures due to known accidental traumas; and previous lumbar spine surgery.

The ESIs at lumbar spine levels for the 352 participants were performed by one staff member. The results of BMD measurements, as well as any fragility fractures, the anatomical site involved, and the treatment administered, were recorded. BMD at the lumbar spine (L2L4), femoral neck, and total femur was measured by dual energy x-ray absorptiometry using Lunar Prodigy (GE Healthcare, Waukesha, WI) and expressed as absolute values $(\mathrm{g} / \mathrm{cm} 2)$. Calibration procedures were performed every day by using appropriate phantoms provided by the manufacturer. The long-term precision of the daily scans of the spine phantom was $0.994 \mathrm{~g} / \mathrm{cm} 2$ in BMD units. The interassay coefficient of variation for BMD was between $0.07 \%$ and $0.09 \%$. BMD values were also expressed as T-scores. T-scores for the bone were calculated by taking the difference between the measured BMD and the mean BMD of healthy young adult Korean women (age, 20-40 years) matched for gender and ethnicity divided by the standard deviation of the young adult population. Osteoporosis was defined as a $\mathrm{T}$ score $<-2.5$ and osteopenia as a $\mathrm{T}$ score $>-2.5$ but $<-1.0$ according to the World Health Organization criteria.

The anteroposterior and lateral radiographs of the thoracic and lumbar spine demonstrating the presence of vertebral fractures were interpreted by radiographic morphometry using Genant's semiquantitative method (29). 


\section{Statistical Analysis}

The data are presented as the mean \pm standard deviation. Unpaired t-test was used to compare differences in age, weight, height, BMD, total number of ESIs, mean duration of glucocorticoid administration, and mean total dose of glucocorticoid between the 2 groups. The prevalence of osteoporosis in the 2 groups was compared using the Mann-Whitney test. Correlation between other variables and BMD was conducted using a Pearson's correlation procedure. Adjustments for age, height, and weight were performed using analysis of covariance. To identify the factors affecting BMD, a multiple linear regression analysis was performed using a stepwise procedure.

In all the comparisons, a $P$ value of less than 0.05 was considered statistically significant. The statistical analyses were performed using SPSS 19.0 (IBM Corporation, Armonk, New York).

\section{Results}

The baseline characteristics of the patients enrolled in the study are presented in Table 1. Of the 352 patients, $218(62 \%)$ had no fractures and 134 (38\%) sustained an osteoporotic fracture. The age was significantly higher among patients who sustained fractures (74 \pm 5.2 years old) than among those without fractures $(65 \pm 7.3$ years old; $P<0.001)$. BMD at the lumbar spine, total femur, and femoral neck regions was significantly lower among patients who sustained fractures (all $P<$ 0.001 ). The overall mean number of ESIs was $4.1 \pm 3.7$, and the mean total dose of glucocorticoid (triamcinolone) was $164 \pm 151 \mathrm{mg}$. There were no statistically significant differences between the 2 groups with respect to weight, height, mean number of ESIs, mean total dose of glucocorticoid, or mean duration of glucocorticoid administration.

The commonest site of osteoporotic fracture was the spine $(63 \%)$, followed by the proximal femur $(23 \%)$ (Table 2). The majority of spinal fractures occurred at the thoracolumbar junction. More than one vertebra was involved in 43 out of 78 patients.

The outcomes of BMD for the lumbar spine, total femur, and femoral neck regions after treatment are listed in Table 3.

In patients treated with ESIs, in the lumbar spine the prevalence of osteopenia was $37 \%$ and for osteoporosis it was 49\%; in the total femur osteopenia was $42 \%$ and osteoporosis was $22 \%$; and in the femoral neck region osteopenia was $52 \%$ and osteoporosis was $23 \%$. The overall prevalence of osteopenia was $37 \%$; for osteoporosis it was $50 \%$.

In patients without fracture, in the lumbar spine the prevalence of osteopenia was $42 \%$ and for osteoporosis it was $38 \%$; in the total femur osteopenia was $40 \%$ and osteoporosis was $11 \%$; and in the femoral neck region osteopenia was $61 \%$ and osteoporosis was $8 \%$.

Table 1. Characteristics of patients and glucocorticoid administration therapy

\begin{tabular}{|c|c|c|c|c|}
\hline & Overall & Without fractures & With fractures & $P$-value \\
\hline Number of patients & 352 & $218(62 \%)$ & $134(38 \%)$ & \\
\hline Age (yrs) & $68(7.8)$ & $65(7.3)$ & $74(5.2)$ & $<0.001^{*}$ \\
\hline Weight (kg) & $57(4.0)$ & $58(3.9)$ & $56(4.1)$ & 0.212 \\
\hline Height $(\mathrm{cm})$ & $159(7.7)$ & $158(7.4)$ & $159(8.2)$ & 0.237 \\
\hline \multicolumn{5}{|l|}{$\mathrm{BMD}(\mathrm{g} / \mathrm{cm} 2)$} \\
\hline Lumbar spine & $0.887(0.272)$ & $0.925(0.234)$ & $0.824(0.320)$ & $<0.001^{*}$ \\
\hline Total femur & $0.767(0.233)$ & $0.819(0.232)$ & $0.682(0.235)$ & $<0.001^{*}$ \\
\hline Femoral neck & $0.711(0.268)$ & $0.754(0.264)$ & $0.641(0.275)$ & $<0.001^{*}$ \\
\hline Mean number of ESIs & $4.1(3.7)$ & $4.0(3.4)$ & $4.5(4.2)$ & 0.390 \\
\hline Mean total dose of glucocorticoid (triamcinolone; $\mathrm{mg}$ ) & $164(151)$ & $158(124)$ & $178(169)$ & 0.311 \\
\hline Mean duration of glucocorticoid administration (wks) & $8.1(7.7)$ & $7.8(5.1)$ & $8.4(7.2)$ & 0.313 \\
\hline
\end{tabular}

Values are expressed as mean (SD)

Abbreviations: ESI, epidural steroid injection; BMD, bone mineral density

${ }^{*} P<0.001$ compared with the "without fractures" group 
In patients with fracture, in the lumbar spine the prevalence of osteopenia was $28 \%$ and for osteoporosis it was $68 \%$; in the total femur osteopenia was $45 \%$ and osteoporosis was $41 \%$; and in the femoral neck region osteopenia was $38 \%$ and osteoporosis was $48 \%$. The overall prevalence of osteoporosis was $38 \%$ in patients

Table 2. Sites of fractures $(\boldsymbol{n}=134)$.

\begin{tabular}{|l|c|}
\hline Site of fracture & Numbers of patients (\%) \\
\hline Ulnar and radius & $12(10)$ \\
\hline Femur & $28(23)$ \\
\hline Spine & $78(63)$ \\
\hline Pelvis & $8(6)$ \\
\hline Humerus & $4(3)$ \\
\hline Tibia and fibula & $4(3)$ \\
\hline Multiple fractures & $10(8)$ \\
\hline
\end{tabular}

without fracture and $69 \%$ in patients with fracture. In each region, the prevalence of osteoporosis was significantly higher in patients with fracture than in patients without fracture (all $P<0.05$ ).

The correlations between BMD and age, weight, height, total number of ESIs, mean duration of glucocorticoid administration, and mean total dose of glucocorticoid are presented in Table 4. In univariate analysis, a positive correlation was observed between BMD and weight at the lumbar spine $(P<0.001)$, the total femur $(P<0.001)$, and the femoral neck $(P<0.05)$; and between BMD and height at the lumbar spine ( $P$ $<0.001)$ and the total femur $(P<0.05)$. A negative correlation was observed between BMD and age at the lumbar spine $(P<0.001)$, the total femur $(P<0.001)$, and the femoral neck $(P<0.001)$. An analysis following adjustment for age, weight, and height revealed that there was no significantly consistent correlation

Table 3. Prevalence of osteoporosis and osteopeniaa in patients treated with ESI and in those with or without fractures

\begin{tabular}{|c|c|c|c|c|c|c|c|c|c|}
\hline & \multicolumn{3}{|c|}{ Normal } & \multicolumn{3}{|c|}{ Osteopeniab } & \multicolumn{3}{|c|}{ Osteoporosise } \\
\hline & $\begin{array}{c}\text { ESI } \\
(\mathrm{n}=352)\end{array}$ & $\begin{array}{l}\text { Without } \\
\text { fractures } \\
(\mathrm{n}=218)\end{array}$ & $\begin{array}{c}\text { With } \\
\text { fractures } \\
(\mathrm{n}=134)\end{array}$ & $\begin{array}{c}\text { ESI } \\
(\mathrm{n}=352)\end{array}$ & $\begin{array}{l}\text { Without } \\
\text { fractures } \\
(\mathrm{n}=218)\end{array}$ & $\begin{array}{c}\text { With } \\
\text { fractures } \\
(\mathrm{n}=134)\end{array}$ & $\begin{array}{c}\text { ESI }(\mathrm{n}= \\
352)\end{array}$ & $\begin{array}{l}\text { Without } \\
\text { fractures } \\
(\mathrm{n}=218)\end{array}$ & $\begin{array}{c}\text { With } \\
\text { fractures } \\
(\mathrm{n}=134)\end{array}$ \\
\hline Lumbar spine $^{d}$ & $\begin{array}{l}49 / 352 \\
(14 \%)\end{array}$ & $\begin{array}{l}44 / 218 \\
(20 \%)\end{array}$ & $\begin{array}{l}5 / 134 \\
(4 \%)\end{array}$ & $\begin{array}{c}130 / 352 \\
(37 \%)\end{array}$ & $\begin{array}{l}92 / 218 \\
(42 \%)\end{array}$ & $\begin{array}{c}38 / 134 \\
(28 \%)\end{array}$ & $\begin{array}{c}173 / 352 \\
(49 \%)\end{array}$ & $\begin{array}{c}82 / 218 \\
(38 \%)\end{array}$ & $\begin{array}{c}91 / 134^{\star} \\
(68 \%)\end{array}$ \\
\hline Total femur ${ }^{\mathrm{d}}$ & $\begin{array}{c}127 / 352 \\
(36 \%)\end{array}$ & $\begin{array}{c}108 / 218 \\
(49 \%)\end{array}$ & $\begin{array}{l}19 / 134 \\
(14 \%)\end{array}$ & $\begin{array}{c}147 / 352 \\
(42 \%)\end{array}$ & $\begin{array}{c}87 / 218 \\
(40 \%)\end{array}$ & $\begin{array}{l}60 / 134 \\
(45 \%)\end{array}$ & $\begin{array}{c}78 / 352 \\
(22 \%)\end{array}$ & $\begin{array}{c}23 / 218 \\
(11 \%)\end{array}$ & $\begin{array}{c}55 / 134^{*} \\
(41 \%)\end{array}$ \\
\hline Femoral neck $^{\mathrm{d}}$ & $\begin{array}{l}87 / 352 \\
(25 \%)\end{array}$ & $\begin{array}{c}68 / 218 \\
(31 \%)\end{array}$ & $\begin{array}{l}19 / 134 \\
(14 \%)\end{array}$ & $\begin{array}{c}184 / 352 \\
(52 \%)\end{array}$ & $\begin{array}{c}133 / 218 \\
(61 \%)\end{array}$ & $\begin{array}{l}51 / 134 \\
(38 \%)\end{array}$ & $\begin{array}{l}81 / 352 \\
(23 \%)\end{array}$ & $17 / 218(8 \%)$ & $\begin{array}{c}64 / 134^{*} \\
(48 \%)\end{array}$ \\
\hline $\begin{array}{l}\text { Overall } \\
\text { prevalence }^{\mathrm{d}}\end{array}$ & $\begin{array}{l}47 / 352 \\
(13 \%)\end{array}$ & $\begin{array}{l}44 / 218 \\
(20 \%)\end{array}$ & $\begin{array}{l}5 / 134 \\
(4 \%)\end{array}$ & $\begin{array}{c}131 / 352 \\
(37 \%)\end{array}$ & $\begin{array}{c}92 / 218 \\
(42 \%)\end{array}$ & $\begin{array}{c}37 / 134 \\
(27 \%)\end{array}$ & $\begin{array}{c}174 / 352 \\
(50 \%)\end{array}$ & $\begin{array}{c}82 / 218 \\
(38 \%)\end{array}$ & $\begin{array}{c}92 / 134^{*} \\
(69 \%)\end{array}$ \\
\hline
\end{tabular}

a BMD data are based on T-scores

b Osteopenia was defined as $-2.5 \mathrm{SD}<\mathrm{BMD} \mathrm{T}$ score $<-1.0 \mathrm{SD}$

c Osteoporosis was defined as BMD T score $\leq-2.5 \mathrm{SD}$ d Values represent the number of patients/total patients (\%)

Abbreviations: ESI, epidural steroid injection

${ }^{\star} P<0.05$ compared with the "without fractures" group

Table 4. Pearson's correlation analysis between BMD and multiple variables.

\begin{tabular}{|l|l|l|l||}
\hline & Lumbar spine & Total femur & Femoral neck \\
\hline Age & $-0.46^{\dagger}$ & $-0.34^{\dagger}$ & $-0.43^{\dagger}$ \\
\hline Height & $0.19^{\dagger}$ & $0.11^{*}$ & 0.12 \\
\hline Weight & $0.31^{\dagger}$ & $0.26^{\dagger}$ & $0.22^{*}$ \\
\hline Mean number of ESIs & -0.09 & $0.02^{*}$ & 0.07 \\
\hline Mean total dose of glucocorticoid & $-0.02^{+}$ & -0.15 & $0.02^{*}$ \\
\hline Mean duration of glucocorticoid administration & 0.12 & 0.11 & 0.01 \\
\hline
\end{tabular}

Abbreviations: ESI, epidural steroid injection; BMD, bone mineral density

${ }^{\star} P<0.05$ and $\dagger P<0.001$ 
between BMD and total number of ESIs, mean duration of glucocorticoid administration, and mean total dose of glucocorticoid (Table 5).

Table 6 shows the effects of factors associated with BMD in postmenopausal women with low back pain. Age was negatively related to BMD at all anatomical sites involved, whereas weight and height were positively related to BMD. However, our study showed no consistent correlation between BMD and the total number of ESIs or mean duration of glucocorticoid administration.

\section{Discussion}

Our study showed no consistent correlation between BMD and the mean number of ESIs, mean total dose of glucocorticoids, or mean duration of ESIs in the lumbar spine, femoral neck, and total femur of postmenopausal women with low back pain. However, the age, height, and weight were associated with BMD. The age and prevalence of osteoporosis were significantly higher, and BMD was significantly lower in patients who sustained fractures.

With $25-50 \%$ of patients affected (22-24), GIOP remains an important clinical problem. The routes of administration of glucocorticoids and the intervals between doses vary considerably. Glucocorticoids inhibit bone formation besides impairing osteoblast differ- entiation and function (24), ultimately increasing the risk of fracture $(1,2,30)$. The risk of fracture might be transient, but any damage to the skeleton that is sustained may have a long-term adverse impact (22-24). The consequences of glucocorticoid administration are aggravated by chronic inflammation, malnutrition, and reduced physical activity (24).

The true incidence and prevalence of osteoporosis in patients receiving ESI therapy is not known, and few data are available. Although the effects of glucocorticoid treatment on fractures are complicated by the effects of the underlying bone disorders, fracture risk appears to increase with glucocorticoid therapy $(31,32)$. Moreover, the prevalence of osteoporosis is proportional to corticosteroid dosage (32). In postmenopausal Korean women, the prevalence of osteoporosis has been reported to be $51 \%$ in the lumbar spine and $11 \%$ in the femoral neck (33), while the overall prevalence of osteoporosis is $56 \%$ (34). In agreement, in the present study, the prevalence of osteoporosis was $49 \%$ in the lumbar spine and $23 \%$ in the femoral neck, and the overall prevalence was $50 \%$; in women with fractures, however, the prevalence was slightly higher, at $68 \%$ in the lumbar spine, $48 \%$ in the femoral neck, and $69 \%$ overall.

Other studies have shown that the fracture incidence from oral glucocorticoid-induced bone loss is

Table 5. Pearson's correlation analysis between BMD and multiple variables adjusted for age, height, and weight

\begin{tabular}{|l|c|c|c|}
\hline & Lumbar spine & Total femur & Femoral neck \\
\hline Mean numbers of ESIs & -0.02 & $0.01^{\star}$ & 0.03 \\
\hline Mean total dose of glucocorticoid & $-0.02^{\star}$ & -0.18 & $0.02^{\star}$ \\
\hline Mean duration of glucocorticoid administration & 0.11 & 0.06 & 0.05 \\
\hline
\end{tabular}

Abbreviations: ESI, epidural steroid injection; BMD, bone mineral density

${ }^{*} P<0.05$

Table 6. Multiple regression analysis of BMD measurements as the dependent variable.

\begin{tabular}{||l|c|c|c|c|c|c||}
\hline \hline & & Age & Height & Weight & $\begin{array}{c}\text { Mean total dose } \\
\text { of glucocorticoid } \\
\text { (triamcinolone; mg) }\end{array}$ & $\begin{array}{c}\text { Mean } \\
\text { number of } \\
\text { ESIs }\end{array}$ \\
\hline \multirow{2}{*}{ Lumbar spine } & $\beta$ & -0.300 & 0.099 & 0.344 & -0.143 & -0.096 \\
\cline { 2 - 8 } & $P$-value & $<0.001$ & 0.008 & 0.001 & 0.041 & 0.344 \\
\hline \multirow{2}{*}{ Total femur } & $\beta$ & -0.281 & 0.160 & 0.291 & -0.121 & 0.199 \\
\hline \multirow{2}{*}{ Femoral neck } & $P$-value & 0.007 & 0.006 & 0.035 & 0.091 & 0.013 \\
\cline { 2 - 8 } & $\beta$ & -0.30 & -0.094 & 0.164 & 0.191 & 0.133 \\
\hline
\end{tabular}

Abbreviations: ESI, epidural steroid injection; BMD, bone mineral density 
estimated to be 1.3 - to 2.6 -fold higher in people receiving glucocorticoids than in those who are not receiving glucocorticoids $(31,32)$. In a large meta-analysis study of glucocorticoid users, van Staa et al (32) found a relative risk increase of 1.91 for any fracture, 2.86 for vertebral fracture, 1.61 for hip fracture, and 1.13 for forearm fracture. In postmenopausal women recruited from the general population, prevalence of asymptomatic vertebral fractures varied from $12 \%$ to $20.2 \%$ according to different methods to evaluate vertebral morphometrical deformity (35-39). In GIOP, a rate of $13.3 \%-28.0 \%$ has been reported for vertebral fractures $(1,30,40,41)$. This rate seems to increase with age, with $14.8 \%$ having been reported for Korean women with a mean age of 59, and $20.9 \%$ for Korean women aged $60-69$ years (41). In this study, the overall prevalence of fractures in postmenopausal women treated with ESI for low back pain was $38 \%$, and the vertebral column was the most affected, with $63 \%$ of the fractures. The true prevalence rate of vertebral fractures was $22 \%$.

Glucocorticoid-induced bone loss is dose and duration related $(25,32,42-44)$. However, bone loss occurs even with low-dose corticosteroid therapy $(31,32)$. Indeed, van Staa et al (45) have found that doses as low as $2.5 \mathrm{mg}$ prednisolone per day are associated with an increased risk of fractures. Luengo et al (37) found no relationship between the dose of steroids and the prevalence of vertebral fractures, whereas others have reported that the glucocorticoid dose is strongly related to the risk of fracture $(35,36)$. Moreover, de Vries et al (39) have found that the risk of GIOP and associated fractures increase substantially with increasing cumulative exposure, and among patients who receive a daily glucocorticoid dose $\geq 30 \mathrm{mg}$ and whose cumulative exposure was more than $5 \mathrm{~g}$. They also found that the relative risk of osteoporotic fracture was 3.63 in patients who received a daily glucocorticoid dose $\geq 15$ $\mathrm{mg}$, and patients whose cumulative exposure was $\leq 1 \mathrm{~g}$ had a slightly increased risk of osteoporotic fractures. It has been well established that the long-term use of glucocorticoids increases the risk of all osteoporotic fractures, and thus, it is recommended that the use of prednisolone $\geq 5 \mathrm{mg}$ for 3 months or longer requires proper investigation and treatment so as to prevent osteoporosis (22-25).

The onset of fracture risk appears to be very rapid, with the maximum risk of fracture occurring within 3 months of starting therapy $(31,32)$. Furthermore, GIOP is reversible after glucocorticoid treatment is interrupted $(46,47)$. A reduction of fracture risk has been seen after one year of discontinuing therapy with glucocorticoids. There is a rapid decline in bone density during the first few months of glucocorticoid treatment, which continues subsequently at a slower rate. This gradual deterioration in bone density does not appear to influence the risk of fracture further. Furthermore, it would be unlikely that an improvement in bone density could explain the relatively rapid offset of fracture risk after glucocorticoids were stopped. For patients taking intermittent glucocorticoids, the risk of fracture does not appear to increase significantly after 1-2 short courses of glucocorticoid treatment. However, patients with cumulative exposure to greater that one $\mathrm{g}$ prednisolone or an equivalent are at greater risk, which increases further with increasing cumulative glucocorticoid exposure (39). Other typical risk factors for osteoporosis, such as low body weight, advanced age, female gender, and underlying disease, may have an independent and additive effect on bone loss in glucocorticoid-treated patients (22-25).

The risk of fracture rises rapidly with age. Therefore, the absolute increase in fracture risk is much higher in the elderly (45-48). The greatest increase in fracture incidence is seen in postmenopausal women and elderly men. In the present study, the patients with fracture had a mean age of 74 . Previous studies have reported the effects of oral administration of relatively high doses of glucocorticoids on BMD (30-32). However, in the present study, glucocorticoids were administered at comparatively lower doses (mean, $164 \mathrm{mg}$ ). Also, mean duration of glucocorticoid administration was relatively short (mean, 8.1 weeks). Nevertheless, the prevalence of vertebral fractures was similar to that reported in other studies. This result may be caused by older age and underlying diseases causing low back pain.

In this study, age was negatively related to BMD at all sites, whereas weight and height were positively related to BMD. We found age, weight, and height to be correlated with BMD, which was consistent with other studies $(34,36,44,49)$. Moreover, our study showed no consistent correlation between the mean number of ESIs, mean total dose of glucocorticoids, or mean duration of ESIs and BMD. Some previous studies reported no significant relationship between epidural glucocorticoid therapy and BMD in postmenopausal women with low back pain $(50,51)$. In contrast, other studies have noted that those with high-dose glucocorticoid therapy are at risk for lower BMD $(2,24,32)$. This interesting observation may be caused by the difference of doses and 
duration of glucocorticoid administration, and implies that the intermittent use of glucocorticoids with ESIs in postmenopausal women with low back pain is not associated with relevant loss of bone mass. However, cumulative glucocorticoid administration might be associated with decreased BMD.

BMD is a major determinant of the risk of fracture in patients with GIOP (24). Adequate monitoring of bone health and therapeutic intervention are recommended when drugs with an adverse bone safety profile are used, particularly in patients with additional risk factors for osteoporosis $(1,24)$. All patients initiating long-term treatment with glucocorticoids should obtain a baseline BMD of the spine and hip $(1,45)$. There should be a low threshold for offering treatment to patients older than 65 years if the cumulative glucocorticoid exposure exceeds the equivalent of one g prednisolone (39). In previous studies, BMDs were measured at the lumbar spine $(0.99-0.92)$, femoral neck (0.84-0.68), and trochanter $(0.70-0.64)$ in Korean postmenopausal women $(43,52)$. In this study, BMD measurements at the lumbar spine (0.887), femoral neck (0.767), and trochanter (0.711) were similar to those previously reported.
There were some limitations to this study. First, this study is limited by the fact that it was retrospective. Second, the number of cases with very frequent, highdose glucocorticoid injections was small. High-dose corticosteroids are infrequently used in the clinic because of adverse effects. In spite of the above limitations, to our knowledge, this was the first study carried out to evaluate the relationship between BMD, ESIs, and vertebral fractures in postmenopausal women with low back pain.

\section{Conclusion}

In conclusion, older age and lower BMD were associated with osteoporotic fracture in postmenopausal women treated with ESIs for low back pain. The ESIs were not associated with BMD.

\section{Acknowledgments}

This study was supported by a Research Grant from Kangwon National University in 2011. We have no financial or other relationships that might lead to a conflict of interest.

\section{References}

1. Maroutti N, Corrado A, Cantatore FP. Glucocorticoids induced risk of fractures. Panminerva med 2010; 52:339-343.

2. Chiluka VL, Banji D, Banji OJF, Sollu,M, Pandra SB. Glucocorticoid induced osteoporosis. Intern J Pharm Sci Rev Res 2010; 53:124-131.

3. You JW, Cho YH. Foraminal stenosis complicating retained broken epidural needle tip. Korean J Anesthesiol 2010; 59:S69-S72.

4. Manchikanti L, Buenaventura RM, Manchikanti KN, Ruan X, Gupta S, Smith HS, Christo PJ, Ward SP. Effectiveness of therapeutic lumbar transforaminal epidural steroid injections in managing lumbar spinal pain. Pain Physician 2012; 15:E199-E245.

5. Parr AT, Manchikanti L, Hameed $\mathrm{H}$, Conn A, Manchikanti KN, Benyamin RM, Diwan S, Singh V, Abdi S. Caudal epidural injections in the management of chronic low back pain: A systematic appraisal of the literature. Pain Physician 2012; 15:E159-E198.

6. Benyamin RM, Manchikanti L, Parr AT, Diwan SA, Singh V, Falco FJE, Datta S, Abdi S, Hirsch JA. The effectiveness of lumbar interlaminar epidural injections in managing chronic low back and lower extremity pain. Pain Physician 2012; 15: $\mathrm{E}_{363}-\mathrm{E}_{404}$.

7. Diwan SA, Manchikant L, Benyamin RM, Bryce DA, Geffert S, Hameed H, Sharma ML, Abdi S, Falco FJE. Effectiveness of cervical epidural injections in the management of chronic neck and upper extremity pain. Pain Physician 2012; 15:E405-E434.

8. Benyamin RM, Wang VC, Vallejo R, Singh V, Helm S II. A systematic evaluation of thoracic interlaminar epidural injections. Pain Physician 2012; 15:E497E514.

9. Manchikanti L, Singh V, Cash KA, Pampati V, Damron KS, Boswell MV. A randomized, controlled, double-blind trial of fluoroscopic caudal epidural injections in the treatment of lumbar disc herniation and radiculitis. Spine (Phila $\mathrm{Pa}$ 1976) 2011; 36:1897-1905.

10. Manchikanti L, Cash KA, McManus CD, Pampati V, Smith HS. One year results of a randomized, double-blind, active controlled trial of fluoroscopic caudal epidural injections with or without steroids in managing chronic discogenic low back pain without disc herniation or radiculitis. Pain Physician 2011; 14:25-36.

11. Manchikanti L, Cash KA, McManus CD, Pampati $\mathrm{V}$, Benyamin RM. A preliminary report of a randomized double-blind, active controlled trial of fluoroscopic thoracic interlaminar epidural injections in managing chronic thoracic pain. Pain Physician 2010; 13:E357-E369.

12. Manchikanti L, Singh V, Cash KA, Datta S. Management of pain of post lumbar surgery syndrome: One-year results of a randomized, double-blind, active controlled trial of fluoroscopic caudal epidural injections. Pain Physician 2010; 13:509-521.

13. Manchikanti L, Singh V, Falco FJE, Cash KA, Pampati V. Evaluation of the effectiveness of lumbar interlaminar epidural injections in managing chronic pain of lumbar disc herniation or radiculitis: A randomized, double-blind, controlled trial. Pain Physician 2010; 13:343-355.

14. Manchikanti L, Cash KA, Pampati V, Wargo BW, Malla Y. Cervical epidural injections in chronic discogenic neck pain without disc herniation or radiculitis: Preliminary results of a randomized, double-blind, controlled trial. Pain Phy- 
sician 2010; 13:E265-E278.

15. Manchikanti L, Cash KA, McManus CD, Pampati V, Benyamin RM. Preliminary results of a randomized, double-blind, controlled trial of fluoroscopic lumbar interlaminar epidural injections in managing chronic lumbar discogenic pain without disc herniation or radiculitis. Pain Physician 2010; 13:E279-E292.

16. Manchikanti L, Pampati V, Boswell MV, Smith HS, Hirsch JA. Analysis of the growth of epidural injections and costs in the medicare population: A comparative evaluation of 1997, 2002, and 2006 data. Pain Physician 2010; 13:199-212.

17. Manchikanti L, Cash KA, Pampati V, Wargo BW, Malla Y. The effectiveness of fluoroscopic cervical interlaminar epidural injections in managing chronic cervical disc herniation and radiculitis: Preliminary results of a randomized, double-blind, controlled trial. Pain Physician 2010; 13:223-236.

18. Manchikanti L, Pampati V, Cash KA. Protocol for evaluation of the comparative effectiveness of percutaneous adhesiolysis and caudal epidural steroid injections in low back and/or lower extremity pain without post surgery syndrome or spinal stenosis. Pain Physician 2010; 13:E91-E110.

19. Smith CC, Booker T, Schaufele MK, Weiss P. Interlaminar versus transforaminal epidural steroid injections for the treatment of symptomatic lumbar spinal stenosis. Pain Med 2010; 11:15111515 .

20. Gerszten PC, Smuck M, Rathmell JP, Simopoulos TT, Bhagia SM, Mocek CK, Crabtree T, Bloch DA; SPINE Study Group. Plasma disc decompression compared with fluoroscopy-guided transforaminal epidural steroid injections for symptomatic contained lumbar disc herniation: A prospective, randomized, controlled trial. J Neurosurg Spine 2010; 12:357-371.

21. Ackerman WE 3rd, Ahmad M. The efficacy of lumbar epidural steroid injections in patients with lumbar disc herniations. Anesth Analg 2007; 104:1217-1222.

22. Shaker JL, Lukert BP. Osteoporosis associated with excess glucocorticoids. Endoc Metab Clin N Am 2005; 34:341-356.

23. Mazziotti G, Canalis E, MD, Giustina A. Drug-induced osteoporosis: Mechanisms and clinical implications. Am Jr Med 2010; 123:877-884.

24. Bouvard B, Legrand E, Audran M, Chappard D. Glucocorticoid-induced osteo- porosis: A review. Clin Rev Bone Miner Metab 2010; 8:15-26.

25. Gaber TA-ZK, McGlashan KA, Love $S$, Jenner JR, Crisp AJ. Bone density in chronic low back pain. Clin Rehabil 2002; 16:867-870.

26. Manchikanti L, Pampati V, Beyer CD, Damron KS, Cash KA, Moss TL. The effect of neuraxial steroids on weight and bone mass density: A prospective evaluation. Pain Physician 2000; 3:357-366.

27. Kang SS, Hwang B, Son H, Cheong IY, Lee SJ, Chung TY. Changes in bone mineral density in postmenopausal women treated with epidural steroid injections for lower back pain. Pain Physician 2012; 15:229-236.

28. Vandenbroucke JP, Von Elm E, Altman DG, Gøtzsche PC, Mulrow CD, Pocock S), Poole C, Schlesselman J), Egger M; Iniciativa STROBE. Strengthening the reporting of observational studies in epidemiology (STROBE): Explanation and elaboration. Gac Sanit 2009; 23:158.

29. Ferrar L, Jiang G, Adams J, Eastell R. Identification of vertebral fractures: An update. Osteoporos Int 2005; 16:717-728.

30. Mitra R. Adverse effects of corticosteroids on bone metabolism: A review. PM and $R$ 2011; 3:466-471.

31. van Staa TP, Leufkens HG, Abenhaim L, Zhang B, Cooper C. Oral corticosteroids and fracture risk: Relationship to daily and cumulative doses. Rheumatology 2000; 39: 1383-1389.

32. van Staa TP, Leufkens HG, Cooper C. The epidemiology of corticosteroid-induced osteoporosis: A meta-analysis. Osteoporos Int 2002; 13:777-787.

33. Cui LH, Choi JS, Shin MH, Kweon SS, Park KS, Lee YH, Nam HS, Jeong SK, Im JS. Prevalence of osteoporosis and reference data for lumbar spine and hip bone mineral density in a Korean population. J Bone Miner Metab 2008; 26:609-617.

34. Kim KC, Shin DH, Lee SY, Im JA, Lee DC. Relation between obesity and bone mineral density and vertebral fractures in Korean postmenopausal women. Yonsei Med J 2010; 51:857-863.

35. Sosa M, Jodar E, Saavedra P, Navarro MC, Gómez de Tejada MJ, Martín A, Peña P, Gómez J. Postmenopausal Canarian women receiving oral glucocorticoids have an increased prevalence of vertebral fractures and low values of bone mineral density measured by quantitative computer tomography and dual X-ray absorptiometry, without significant changes in parathyroid hor- mone. Eur ] Intern Med 2008; 19:51-56.

36. Naganathan $V$, Jones $G$, Nash P, Nicholson G, Eisman J, Sambrook PN. Vertebral fracture risk with long-term corticosteroid therapy: Prevalence and relation to age, bone density, and corticosteroid use. Arch Intern Med 2000; 160:29172922.

37. Luengo M, Picado C, Del Rio L, Guañabens N, Montserrat JM, Setoain J. Vertebral fractures in steroid dependent asthma and involutional osteoporosis: A comparative study. Thorax 1991; 46:803806.

38. Steinbuch M, Youket TE, Cohen S. Oral glucocorticoid use is associated with an increased risk of fracture. Osteoporos Int 2004; 15:323-328.

39. de Vries F, Bracke M , Leufkens HGM, Lammers J-W J, Cooper C, van Staa TP. Fracture risk with intermittent highdose oral glucocorticoid therapy. Arthritis Rheum 2007; 56:208-214.

40. Al-Osail AM, Sadat-Ali M, Al-Elq AH, AlOmran AS, Azzam Q. Glucocorticoid-related osteoporotic fractures. Singapore Med J 2010; 51:948-951.

41. Shin CS, Kim MJ, Shim SM, Kim JT, Yu $\mathrm{SH}$, Koo BK, Cho HY, Choi HJ, Cho SW, Kim SW, Kim SY, Yang SO, Cho NH. The prevalence and risk factors of vertebral fractures in Korea. J Bone Miner Metab 2012; 30:183-192.

42. Cooper M. Glucocorticoid-induced osteoporosis: How best to avoid fractures. Therap Adv chr Dis 2010; 1:17-23.

43. Jeong IK, Cho SW, Kim SW, Choi HJ, Park KS, Kim SY, Lee HK, Shin CS. Lipid profiles and bone mineral density in pre- and postmenopausal women in Korea. Calcif Tissue Int 2010; 87:507-512.

44. Everdingen AA, Reesema S, Jacobs J, Bijlsma J. Low-dose glucocorticoids in early rheumatoid arthritis: Discordant effects on bone mineral density and fractures? Clin Exp Rheum 2003; 21:155-160.

45. van Staa TP, Leufkens HG, Abenhaim L, Begaud B, Zhang B, Cooper C. Use of oral corticosteroids in the United Kingdom. QJM 2000; 93:105-111.

46. Carbonare LD, Arlot ME, Chavassieux APM, Roux JP, Portero NR, Meunier, PJ. Comparison of trabecular bone microarchitecture and remodeling in glucocorticoid-induced and postmenopausal osteoporosis. J Bone Miner Res 2001; 16:97-103.

47. Laan RF, van Riel PL, van de Putte LB, van Erning LJ, van't Hof MA, Lemmens JA. Low-dose prednisone induces rap- 
id reversible axial bone loss in patients with rheumatoid arthritis. Ann Intern Med 1993; 119:963-968.

48. van Staa TP, Leufkens HG, Abenhaim L, Zhang B, Cooper C. Use of oral corticosteroids and risk of fractures. J Bone Miner Res 2000; 15:993-1000.

49. Hong S, Ahn YH, Choi WH. Age-, gender-and region-related changes in bone mineral density of korean adult. Journal of KSO 2010; 8:188-195.
50. Kang SS, Hwang BM, Son HJ, Cheong IY, Lee SJ, Chung TY. Changes in bone mineral density in postmenopausal women treated with epidural steroid injections for lower back pain. Pain Physician 2012; 15:229-236.

51. Dubois EF, Wagemans MF, Verdouw $B C$, Zwinderman $A H$, Van Boxtel CJ, Dekhuijzen PN, Schweitzer DH. Lack of relationships between cumulative methylprednisolone dose and bone mineral density in healthy men and postmenopausal women with chronic low back pain. Clin Rheumatol 2003; 22:12-17.

52. Park JJ, Shin J, Youn Y, Champagne C, Jin $\mathrm{E}$, Hong $\mathrm{S}$, Jung $\mathrm{K}$, Yeom S. Bone mineral density, body mass index, postmenopausal period and outcomes of low back pain treatment in Korean postmenopausal women. Eur Spine ] 2010; 19;19421947. 
